\title{
Urban microclimates and renewable energy use in cities
}

\author{
Erdal Turkbeyler ${ }^{1}$, Runming Yao ${ }^{1, *}$, Tony Day ${ }^{2}$ \\ ${ }^{I}$ School of Construction Management and Engineering, the University of Reading, \\ Whiteknights, PO Box 219, Reading, RG6 6AW, United Kingdom \\ ${ }^{2}$ Centre for Efficient and Renewable Energy in Buildings (CEREB), Department of Urban Engineering, \\ London South Bank University, London, SE1 OAA, United Kingdom \\ * Corresponding author. Tel: +44 (0)1183786068, Fax: +44 (0)1189313856, E-mail: r.yao@reading.ac.uk
}

\begin{abstract}
This paper presents an experimental measurement campaign of urban microclimate for a building complex located in London, the United Kingdom. The experiment was carried out between $19 \mathrm{July}$ and 16 August, 2010 at the Elephant \& Castle site. The wind and solar energy distributions within the London urban experimental site were assessed in detail for their potential use in areas of high-rise urban building complexes. The climatic variables were measured at every five minutes for the air temperature, the wind speed and direction, the air humidity and the global solar radiation for a period of four weeks. The surface temperatures were also measured on the asphalt road, pavement and building walls at every hour for the first week of the campaign period. The effect of the building complex on the urban microclimate has been analyzed in terms of the solar radiation, the air temperature and velocity. The information and observation obtained from this campaign will be useful to the analysis of renewable energy implementations in dense urban situations.
\end{abstract}

Keywords: London, Urban Climates, Measurement

\section{Introduction}

Effective urban planning and building design can have a beneficial effect on the urban climate and contribute towards reducing the intensity of urban heat island, improving living space, directly reducing the peak cooling load of a building and exploring potential implementation of renewable energy. Passive solar heating of houses in winters and passive cooling in summers provide low cost and sustainable solutions for these preferable outcomes. However, to achieve these solutions in high-rise and densely built urban environments are challenging due to the obstructions at close proximity and existing orientations of roads. Knowledge of microclimatic variables, particularly the urban wind and solar radiation can be used for developing better design options for renewable energy technologies within urban environment or determining their efficient operational conditions in cities.

In the literature, however, the microclimate within an urban complex is reported mainly in the context of air circulation and temperature distribution within urban street canyons, only. In these studies, the geometric characteristic of the urban layout is idealized as infinite parallel walls of street canyons. Santamouris et al. [1] studied the thermal characteristics in a deep $(\mathrm{H} / \mathrm{W}=2.5)$ pedestrian canyon with a NW-SE axis, under hot weather conditions in Athens, during summer 1997. It has been observed a surface temperature difference of up to $19{ }^{\circ} \mathrm{C}$, between opposite building walls. Air temperature difference near the two opposite facades varied up to $4.5^{\circ} \mathrm{C}$ due to the impact of convection heat transfer from adjacent wall surfaces.

Similarly, Niachou and et al. [2] also reported an experimental study of a typical street canyon $(\mathrm{H} / \mathrm{W}=1.7)$ oriented in ESE-WNW direction in Athens, again under hot weather conditions in 2002. The measured surface temperature difference across the street reached almost $30{ }^{\circ} \mathrm{C}$ and this caused the overheating of lower air levels. The microclimate in urban street canyons is also investigated by numerical studies $[3,4,5$,], with emphasis on pe destrian comfort, pollutant dispersion and natural ventilation. For an urban district, an experimental 
investigation for the distribution of solar energy and wind energy for a general, random city layout was not available in the literature.

The present study investigates - unlike a simple layout of a street canyon, a general geometric characteristic of urban layout with high-rise and intensely spaced building complexes that are mixed with middle-rise buildings. The main objectives of this experimental investigation are: to quantify the temporal and spatial distribution of microclimatic variables for an urban site; to study the impact of the layout and orientation of buildings on these variables; and to assess the availability of the solar and wind energy within an urban building complex for their potential use, either actively or passively.

For this purpose, within a London urban district of the Elephant \& Castle, the accessibility to the renewable energies- both the solar and wind energies, was studied experimentally by a field measurement campaign between 19 July and 16 August, 2010. The air temperature, the wind speed and direction, the air humidity and the global solar radiation were measured at four locations within a high rise building complex at the London site. The maximum distance between the measurement locations was $130 \mathrm{~m}$. Effects of the urban building complex on the thermal and airflow characteristics of the resulting microclimates were analyzed in detail. The surface temperatures of building walls and ground were also measured at these locations. The observed characteristics of urban microclimate at the London experimental site and the findings of the present study are presented in this paper.

\section{Experimental method}

\subsection{Experimental site}

London is located in the south of England, UK., and has an elevation of $24 \mathrm{~m}$. It enjoys a temperate marine climate. The Elephant \& Castle site has a global location of $51^{\circ} 29^{\prime} \mathrm{N}$ and $0^{\circ}$ $06^{\prime} \mathrm{W}$. Figure 1 displays the London urban experimental site and the measurement points: 3, 4, 5 and 6 . The experimental site was chosen for its high rise buildings and contrasting street layouts. The physical characteristics of the urban space are presented in Table 1. The London South Bank University Southwark campus occupies the central part of the experimental site. At the time of the experiments, a 32m high K2 building of the campus (Fig.1) had replaced previous low-rise buildings at the same location.

Four automatic weather stations (WS) were installed to the street-lighting columns that are located at the Ontario Street (3), Keyworth Street (4), the Thomas Doyle Street (5) and the Borough Road (6). The Keyworth Street (4) represents an urban street canyon linking Ontario Street (3) and Borough Road (6), and has a length of 230 meters. The weather station 3 that was installed at the dead end of Ontario Street faces the back of the surrounding buildings in every direction. The street level views of these four streets are displayed in Fig.2. 


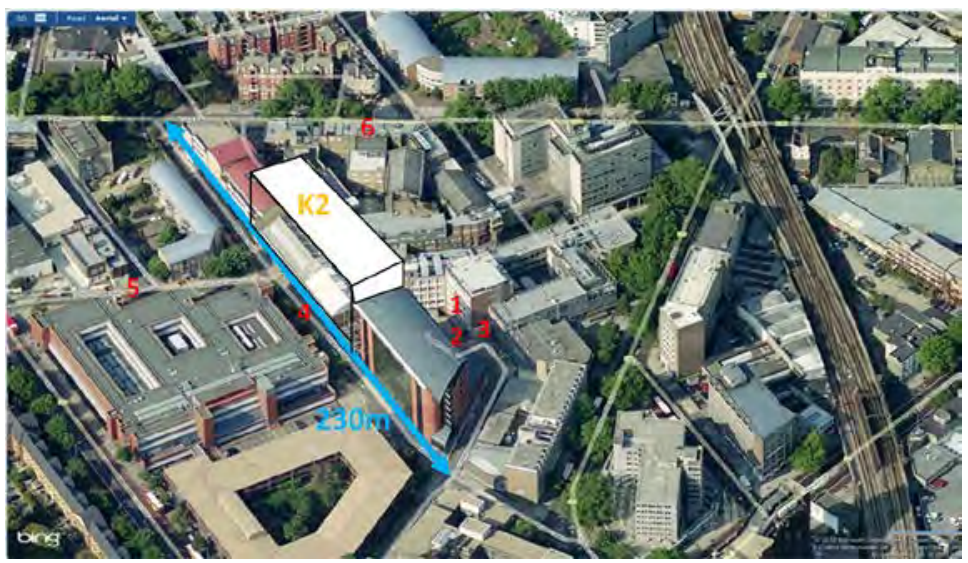

Fig. 1. London urban experimental site at Elephant \& Castle (locations of weather stations: 3, 4, 5, 6)

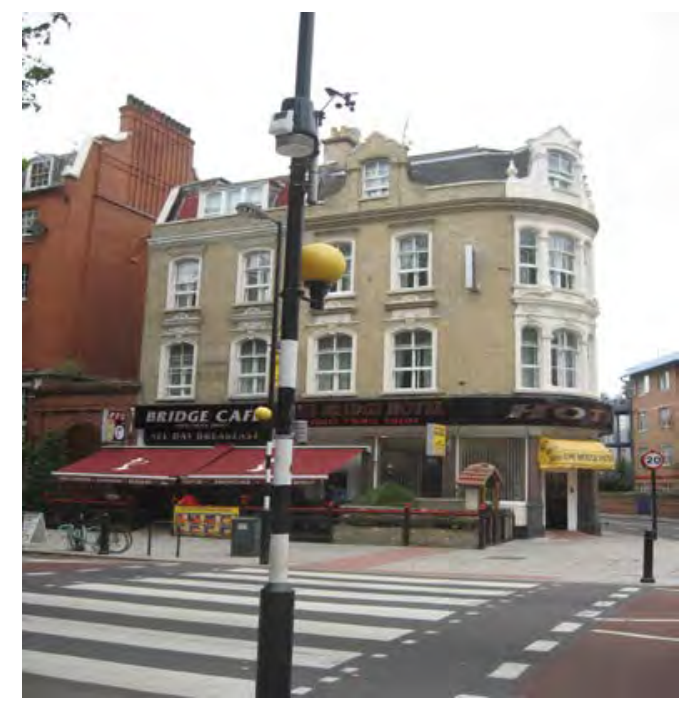

Borough Road (WS-6)

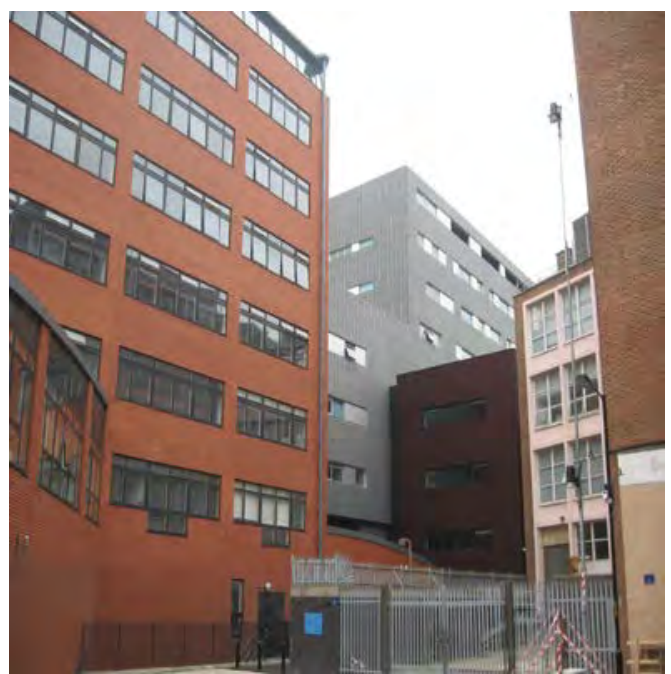

End of Ontario Street (WS-3)

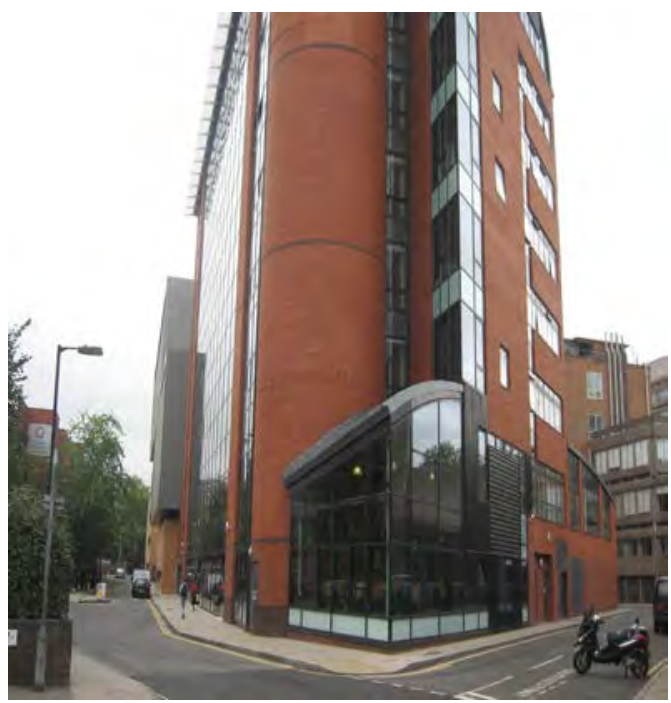

Keyworth Street (WS-4)

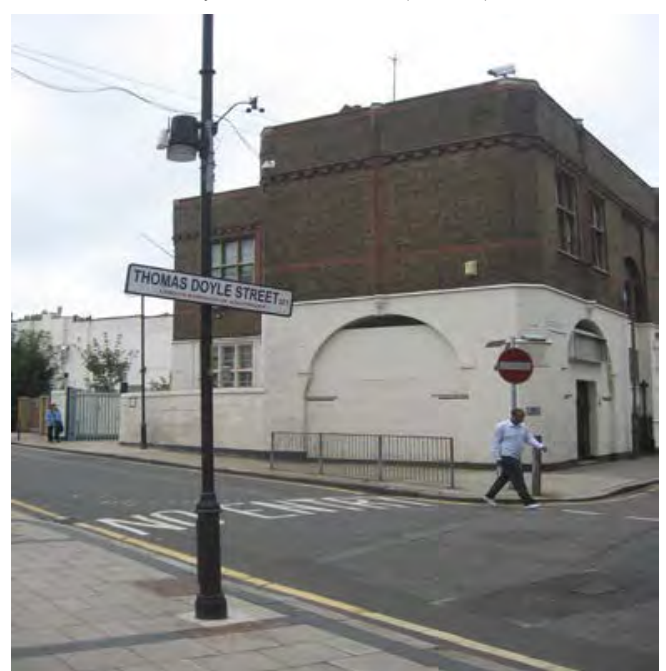

Thomas Doyle St. (WS-5)

Fig. 2 Street views of the London experimental site at Elephant \& Castle Borough 
Table 1. Characteristics of four streets at the London experimental site.

\begin{tabular}{ccccc}
\hline Street name & $\begin{array}{c}\text { Street } \\
\text { orientation }\end{array}$ & $\begin{array}{c}\text { Weather } \\
\text { Station No }\end{array}$ & Traffic conditions & Vegetation \\
\hline Ontario St. & SSW to NNE & WS-3 & Access only & None \\
\hline Keyworth Street & SE to NW & WS-4 & One way, low traffic & Trees at one side \\
\hline Thomas Doyle St. & SW to NE & WS-5 & One way, low traffic & None \\
\hline Borough Road & WSW to ENE & WS-6 & Two way, main road & Trees at both sides \\
\hline
\end{tabular}

Table 2. The geometry and material information of London experimental site

$\begin{array}{ccccc}\text { Street name } & \mathrm{W}(\mathrm{m}): & \mathrm{H} / \mathrm{W}: & \text { Building } \\ & \text { Street width } & \text { Ratios of building } & \text { materials }\end{array}$
heights $\{\mathrm{H}\}$ to $\mathrm{W}$

\begin{tabular}{ccccc}
\hline Ontario St. & 14 & $0.57-2.00$ & Bricks, concrete & $0.10-0.35$ \\
\hline Keyworth Street & 12 & $0.75-2.66$ & Bricks & $0.20-0.35$ \\
\hline Thomas Doyle St. & 14 & $0.64-0.87$ & Bricks & $0.20-0.35$ \\
\hline Borough Road & 22 & $0.45-0.68$ & Bricks & $0.20-0.35$ \\
\hline
\end{tabular}

In table 2, for each street, the spacing between buildings (W) across the street including the pavements and the ratio of building heights $(\mathrm{H})$ to spacing between the buildings $(\mathrm{W})$ are listed alongside the type of building materials and their albedo values. The range of $\mathrm{H} / \mathrm{W}$ ratios at each street represents all buildings along the street.

\subsection{Parameters of measurements}

At each measurement location $(3,4,5$ and 6), the air temperature, the wind speed and direction, the air humidity and the global solar radiation were recorded by an automatic weather station - Davis Wireless Vantage Pro2, Fig.3, which was attached at a height of $4 \mathrm{~m}$ to a s treet-lighting column. The weather station 3 (WS-3) is located at the-dead-end of the Ontario Street, but, the other columns are positioned at the mid-distance of the streets. The accuracy of the integrated sensor suite (ISS) of the weather station for measuring each climatic variable is $0.56^{\circ} \mathrm{C}$ for air temperature, $\pm 5 \%$ for the wind speed, $\pm 7 \mathrm{deg}$ for the wind direction, $\pm 3 \%$ for the air humidity and $\pm 5 \%$ for the solar radiation. At each street lightingcolumn location, the surface temperatures were also measured on the asphalt road, pavement and building walls at every hour. A K-type thermocouple digital thermometer - Model WK026, is used for the surface measurements.

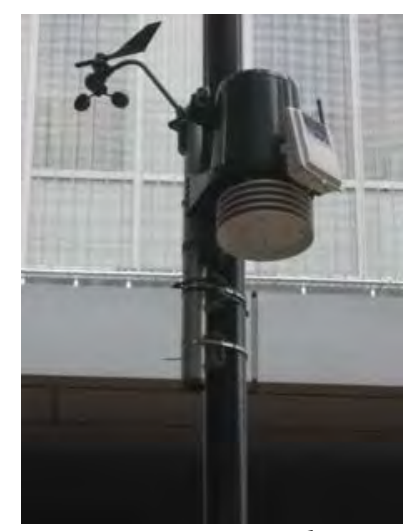

Fig. 3 A view of the automatic weather station, positioned at $4 m$. 


\subsection{Duration of field measurements}

The measurement campaign was carried out between 19 July and 16 August, 2010. The microclimatic variables were measured at every five minutes during the campaign period. During the first week of the campaign: $19-23$ July, the surface temperatures were also measured every hour, over a period of five days.

\section{Results}

The experimental observations of the microclimatic variables at the London urban site are presented here for the air temperature, the air speed and the solar radiation. Figure 4 displays the evolutions of air temperatures at four locations over a 24 hours period from the midnight to midnight on 24 July 2010. During the day time, the air at the dead end of the Ontario Street (WS-3) is generally warmer than the air at the Borough Road (WS-6). The air temperatures at other locations remains between these bounding values of WS-3 and WS-6 However, the air temperatures at all locations get closer each other's value at the night time. The pattern in Fig. 4 has observed also for the other days of the experimental campaign period. For example, Fig. 5 displays the air temperature evolutions at the locations of WS-3 and WS-6 for an interval of one week, between 2 and 8 A ugust 2010. The factors affecting this pattern are discussed in section 4 , below.

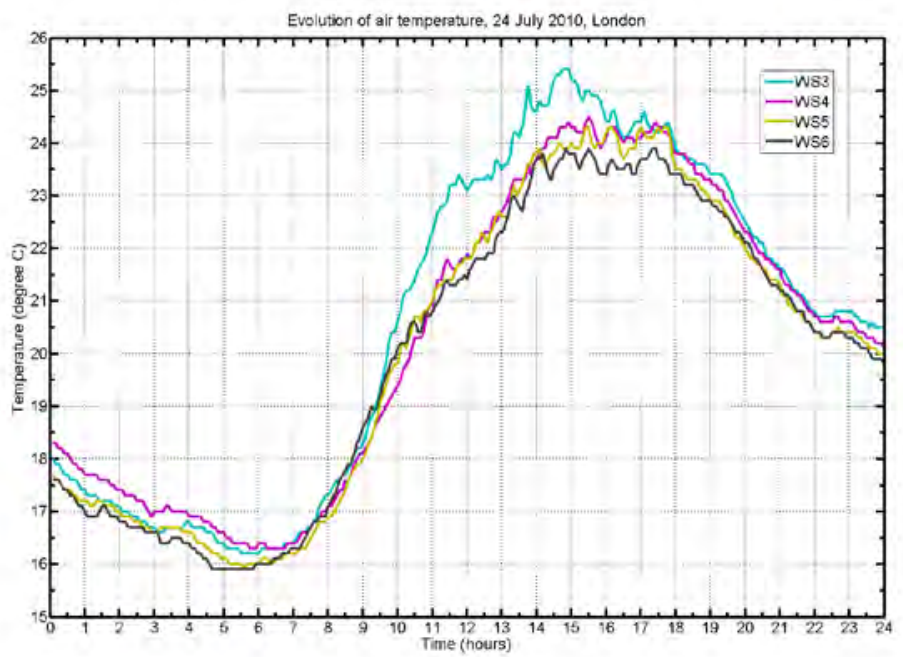

Fig. 4 Air temperature distributions at the London experimental site on 24 July 2010

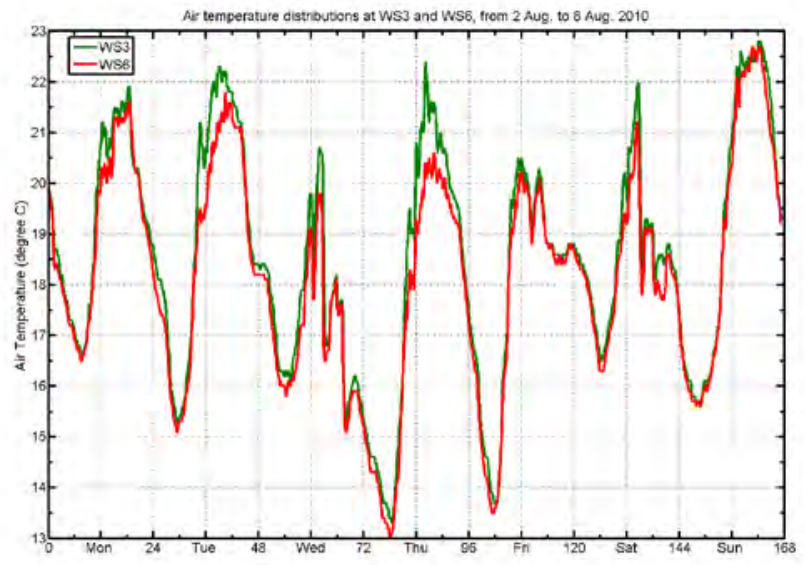

Fig. 5 Weekly air temperature evolutions at the dead-end of Ontario Street (WS3) and the Borough Road (WS6), 2 - 8 August, 2010 


\section{Discussion and conclusions}

The layout of buildings and their orientations interact with the wind and the solar radiation and this interaction forms the different microclimates at each location. As is observed from these experimental results, Figs 4 and 5, the variation of air temperatures from location to location is an outcome of this interaction. Similarly, in an urban environment, the renewable energy use - solar or wind energy is also affected by spacing between buildings, building heights and their layout and orientations. For the measurement points of WS-3, WS-4, WS-5 and WS-6, the variation of the daily solar energy received by a horizontal surface over a period of one week and the variation of daily windiness over the same period are displayed in Figs. 6 and 7. Two new derived variables are calculated for this purpose; theyare wind run and the solar energy received at a given location over a time period.

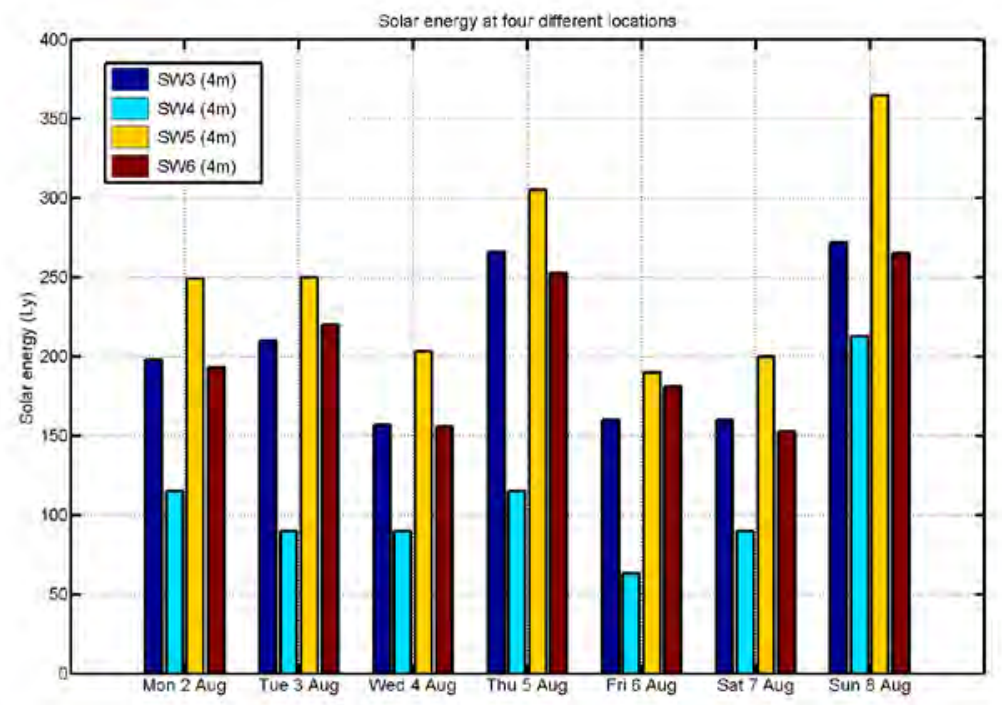

Fig. 6 Daily solar energy variation at the London experimental site, from 2 to 8 August 2010

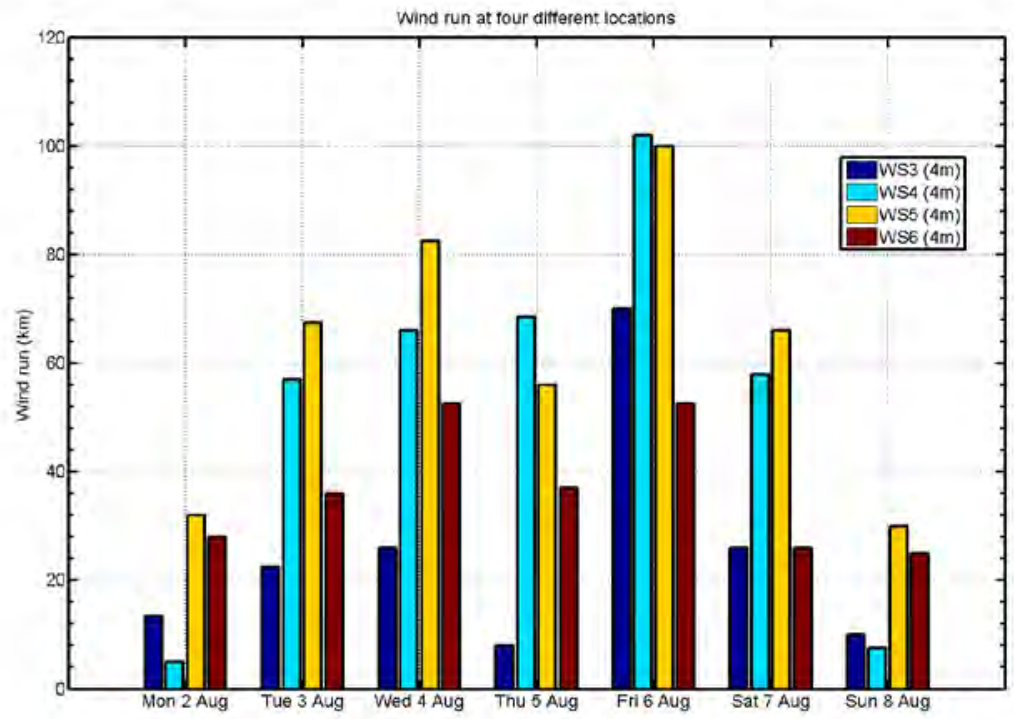

Fig. 7 Windiness of the London experimental site between 2 and 8 August 2010 
Wind run presents the "amount" of wind passing the location of the weather station during a given period of time, expressed in "kilometers of wind". It is calculated by multiplying the average wind speed for each archive record by the archive interval of five minutes. By taking into account the variation of the solar radiation arriving at a location due to the position of the sun in sky, the passing clouds and shade movements, the resulting solar energy received over a time interval is also calculated. The average value of the solar radiation (watt per square meter) for each archive record is multiplied by the archive interval of five minutes to calculate the solar energy for the archive interval. The solar energy is measured in Langley (Ly): 1 Langley $=11.622$ Watt-hours per square meter.

On Friday, 6 August, the dominant wind direction above the roof of K2 Building (32m) was in the SE direction, which coincides with the axis of the Keyworth Street (WS-4). As a result, WS-4 reaches the highest daily wind run value for this week, Fig.7. During the week, the dead-end of Ontario Street (WS-3) was the most sheltered one, and also having high values of the solar energy. As a consequence, the air at the dead end of Ontario Street (WS-3) warms up the most among all the locations, as was observed in Figs. 4 and 5.

On the other hand, while the Thomas Doyle St. (WS-5) also receives a high value of solar energy due to the less obstruction against the sun light, this street also a windy one. As a result, the air at WS-5 does not warm up as much as like the air at Ontario Street (WS-3). The urban street canyon effect at the Keyworth Street (WS-4) can easily be observed from Fig.6 as the reduced solar energy at there.

In this paper, the results of the experimental measurement campaigns for studying urban microclimates for high-rise building complexes in London are presented. Implications on using the solar and wind energy in urban environments are analyzed. It has been demonstrated that the layout and orientation of buildings cause the variation of microclimate from one location to another. While, the tree-lined road was relatively cooler, the urban street canyon received the direct solar radiation only for a limited period, thus also remained relatively cooler. Whereas, the air in the non-green area has trapped the most heat and the air temperature has reached its highest value. It can be concluded that the buildings are operating against their own individual microclimatic variables rather than the meteorological weather data and that a buildings microclimate is affected by the existence of other buildings.

\section{Acknowledgements}

The authors would like to thank the finance support from the UK Engineering and Physical Sciences Research Council (EPSRC EP/F039867/1) and the support from the partners of the Chartered Institution of Building Services Engineering, Max Fordham, Short and Associates, MTT Consulting and Chongqing University.

\section{References}

[1] M. Santamouris, N. Papanikolaou, I. Koronakis, I. Livada, D.N. Assimakopoulos, Thermal and air flow characteristics in a d eep pedestrian canyon and hot weather conditions. Atmospheric Environment, 33(1999) 4503-21

[2] K.Niachou, I. Livada, M Santamouris, Experimental study of temperature and airflow distribution inside an urban street canyon during hot summer weather conditions-Part I: Air and surface temperatures., Building and Environment, 43 (2008) 1383-1392. 
[3] T. J. Williamson, E. Erell., Thermal performance simulation and the urban microclimate: measurements and prediction., Proc. of IBPSA Conference Building Simulation'2001, pp.159-165.

[4] F. Sanchez de la Flor, S. Alvarez Dominguez., Modeling microclimate in urban environments and assessing its influence on the performance of surrounding buildings, Energy and Buildings, 36 (2004) 403-413.

[5] E. Bozonnet, R. Belarbi, F. Allard, Modeling solar effects on the heat and mass transfer in a street canyon, a simplified approach, Solar Energy 79 (2005) 10-24. 